\title{
Positioning gamers within identities
}

Daniel de Augustinis Silva

UFRJ-Macaé, Avenida do Aloísio, 50- Granja dos Cavaleiros

\section{ABSTRACT}

Macaé, RJ, CEP 27930-560 Brasil

\begin{abstract}
In this paper, we describe the language used in a particular educational video game, Quest Atlantis (QA). We begin by reviewing a number of works which deal with video games and come to the conclusion that, although many speak of aligning the player with a particular identity (cf. footing, Goffman, 1981) which is necessary to achieve particular tasks, none of these works deal specifically with the role language plays in the construction of these personae. Therefore, we describe the language used in a single task in QA, revealing the generic structure (Hasan, 1985) of these prompts. After that, we observe how language is used at the level of the sentence with the analysis of deictics (Ochs, 1992; Hanks, 1992). We conclude that more interactions within QA need to analyzed before we reach a more definite answer to our questions, but the language resources revealed here will certainly provide educators and game with a more tangible framework with which to position learners and players.
\end{abstract}

\section{Indexing terms/Keywords}

Online learning environments, video games, genres, appraisal, culture

\section{Academic Discipline And Sub-Disciplines}

Education; Cultural Studies; Applied Linguistics; Genre studies

\section{SUBJECT CLASSIFICATION}

Language and culture.

\section{TYPE (METHOD/APPROACH)}

Discourse analysis; deictics analysis.

\section{Council for Innovative Research}

Peer Review Research Publishing System

Vol.3, No.1

editor@ijssronline.com

www.cirworld.com, www.ijssronline.com 


\section{INTRODUCTION}

In What Video Games Have to Teach us about Learning and Literacy, James Gee discusses thirty-six learning principles embedded in what he called good video games, some of which I have decided to focus this paper on. One is the Psychosocial Moratorium Principle, which entails that real-world consequences are lowered. That means that the dangers of losing face are less great than in a classroom, for instance. Besides, the environment is multimodal, providing a learning experience full of visual and acoustic elements, besides the written word (The Multimodal Principle). Next, the Identity Principle states that, while playing, it is possible to take on specific identities. These identities, I will argue, are made available discursively along particular games. Finally, there is the Situated Meaning Principle, which states that the meanings of signs are situated in embodied experience, so meanings are not decontextualized, but rather anchored in the gamer's actions, and the Transfer Principle, which says that the learning constructed in the games can be used to solve real-world problems. Although research which focuses on games and gaming is relatively new, it is not hard to find other researchers who will give support to what Gee has written.

Barab et al (2012), for instance, make the point that the learning that takes place within a video game (I will use the words game and video game interchangeably in this paper, meaning both games that you play on a console or on a computer) offers better results, due to the fact that the participants are aligned with the necessary identities required to learn a particular content. Siyahhan et al (2011) have observed, with the help of a game, that, the higher the commitment to the representation of a particular identity, the more careful and thoughtful students were at making choices, whereas the same situation, taken outside of its context, received a much more categorical and absolutist response. Barab et al (2010: 18) argue that "games allow us to additionally situate the person as the central protagonist who makes key decisions". Siyahhan et al (2010) observes which footings are offered and taken while a group of parent-child pairs play Quest Atlantis, focusing on the parent-child dyad. They conclude that, while parents and children may use technology differently, there is room for facilitating bonding and family relations within Quest Atlantis. The same probably happens in other games. In the corpus I have been creating, one of the research participants describe how his father used to help him play Pokémon.

Table 1: Report of interaction between a Brazilian boy and his father.

Researcher: So you were 9.

Gabriel: Yeah, around that, 9, 10.

Researcher: Ok, so you couldn't read in English then.

Gabriel: No, no.

Researcher: But you played!

Gabriel: But I played!

Gabriel: My parents could read in English.

Gabriel: Hahaha

Gabriel: At the time, their English was good actually.

Gabriel: So, my dad went there, I would make my father translate what was being said and I would play.

Researcher: So did you ever come to play by yourself?

Gabriel: After I finished - I played Yellow first, then Blue, then Red. After I finished Blue, I was able to play the other two by myself because it was very intuitive. A lot of things were similar, I mean, the things I had to do.

As will have been clear from the interaction above, the dyad revealed is the expected parent-child dyad only until the first game is finished. After that, the design grammar (Gee, 2003) of the game has already been learned, so the language problem is compensated for with the help of the game's design. It can be said, then, that after finishing Pokémon Yellow, the boy becomes ready to take on the game by himself.

Gaming is not only about learning in itself, however. A different group of researchers have started looking at hoe ideology has been manifested in and around games. Alexander et al (2007), for instance, takes a glimpse at a specific event while he, a gay man, was playing with a group of heterosexual men. He builds his point around the fact that a prejudiced commented emerged in one of the interactions. This fact led to the consideration that there is a lack of studies considering the interconnection between gaming, sexuality and literacy. His paper is exploratory, but it still sheds light on much still needs to be done in regard to gaming and other aspects of social life.

183 | P a g e 
Blackmon et al (2007) focuses on racial representation in video games, arguing that most protagonists are centered on the white-male-heterosexual mind in two ways. The first is that there are just more whilte, male, heterosexual protagonists than alternative protagonists. The second is that, when there are actually alternative protagonists, such as women and blacks, they are represented in ways less than satisfactory to the members who align themselves with these groups. Another researcher who writes about the privilege of manhoodin games is Pamela Takayoshi. She examines how the gaming industry has been traditionally biased towards the male population, concluding that few games have female characters, and even fewer games with empowered females which her research participants could identify with.

As it has been shown, a lot has been written about games in how they provide specific footings (Goffman, 1981) to be taken up by gamers, both in terms of power relationships and terms of learning, more generally. However, in the literature reviewed there is no work which attempts to cross the status of game prompts as genres and what their language is like.

Therefore, considering that Quest Atlantis is a good game (cf. Gee, 2003), this paper aims at:

a) Describing how game prompts are structured as a genre;

b) Describing the language which is prototypical of this genre.

c) Describing how these prompts build a particular identity for the gamer.

In the next section, we will review where we stand in relation to the spistemic status of genres and how they can be approached in different ways. After that, we will briefly outline the steps we took to select and analyze the data. Next, the analysis itself will be presented, revealing the results we obtained. Finally, we make some final remarks, wrapping up the paper and establishing an agenda of future steps.

\section{GENRES}

Rojo (2008[2006]) discusses the concept of genres by focusing on the epistemic status of genres in post-modernity. She argues for the inclusion of the study of genres in the classroom because they necessarily deal with language in a highly specific context. In other words, she walks away from a homogeneous view of language usually prescribe by grammarians. The predominant view is that of communities of practice (Pratt, 1987), which presupposes that language can only be understood if it is analyzed in the context where it occurs. Therefore, the idea of one single language disappears, lending support to variations of language which are as important (Makoni and Pennycook, 2006) as the standard language advocated by purists.

Rojo's stance is reinforced by Signorini (2006[2008]), who understands the various ways of speaking that exist as performances of identity (Bauman, 1986; Langellier, 2001; Threadgold, 2005; Thornborrow and Coates, 2005) which emerge from particular interactions in a particular moment. Another researcher who argues in favor of thinking about genres is Hoey (2004), who refers to the use of decontextualized texts as "Cinderella texts". Therefore, it is possible to assume that there are stable discourses which flow within particular communities (cf. affinity groups, Gee, 2003) - and by stable I do not mean that they do not change, but rather that they index the identity of a particular group (Hanks, 1992; Ochs, 1992) - which become tangible when they are organized into a genre.

Instead of considering that there is only one correct language, it becomes necessary to think about language games (Wittgenstein, 1953) which emerge with the identities we seek to echo. If we examine Bakhtin (1979[1992]), it is possible to infer that the theorist considered that nothing we say is ever new; everything has been said before, arguing that "if the genres did not exist, if we had to create them for the first time as we speak, if we had to construct every single one of our utterances, verbal communication would be almost impossible" (Bakhtin, 1979[1992]). This view is in line with Gee's position that we can never think in general, that we are always thining in a particular way (Gee, 2003), even if we may change this particular footing across utterances. Gee (2003) argues, for instance, that, in his case, he could read the Bible as literature, as theology and as a religious skeptic.

Having established the importance of studying genres, it now becomes necessary to understand what genres mean to particular groups of people. Hyon (2000) identifies three traditions of approaching genres, the English for Specific Purposes (ESP) tradition, the American New Rhetoric, and the Australian tradition of the Systemic-Functional Linguistics (SFL).

According to Hyon (op.cit.: 695), the ESP tradition focuses mainly on formal elements, considering genres to be a tool for teaching academic and professional genres to non-native learners of the language. While the ESP brings powerful tools to describe genres - especially written genres - it fails to consider their specialized functions and their social context. The American New Rhetoric, according to her, focuses too much on the social context while not paying so much attention to formal elements. Finally the SFL tradition would be worried with the relationship between language and its functions in the social context (Hyon, op. cit.: 696-697). Language then takes shape according to the field, tenor and mode of the interaction, or, the register. 
In our analysis, we will use the theoretical framework of the SFL. According to a systemic-functional perspective, genres can be described according to their mandatory and optional elements. A notation used by Hasan (1985) and a sample description of a transaction in Cyrenaica can be found below.

$[(\text { Greeting })(\text { Sale start })]^{\wedge}\left[(\text { Inquiry about a product })^{n} \wedge\right.$ \{Purchase request $\wedge^{\wedge}$ Conformity with the request ${ }^{n} \wedge$ Purchase $]$ Purchase closure ${ }^{\wedge}$ (Conclusion)

Table 2: Notation used by Hasan (1985).

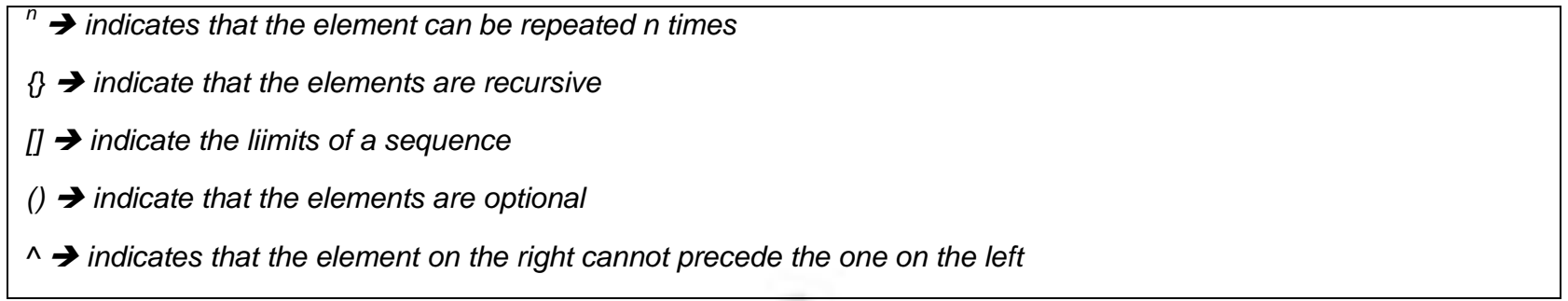

As can be seen above, Hasan's notation shows us that, in Cyrenaica, the only necessary steps to enact a purchase were 1) to request to buy something, 2) that the seller was in accordance with the request, and 3) the purchase itself. This process can be repeated many times before the sales transaction finally comes to an end.

We have seen that the study of genres is important if we consider that language is dynamic and variable across affinity groups. The most important conclusion in studying is probably the fact that we open the dominant language variant to scrutiny, calling attention to the fact that there are many variations which are not less important. We have also seen that the theoretical framework used in this paper is the one advocated by Hasan (1985), where obligatory and optional elements can be seen. In the next section, we will detail how the data were generated and treated.

\section{METHODS}

As mentioned in the introduction, this paper aims at describing how game prompts are structured as a genre, the language which is prototypical of the genre, and how these prompts build a particular identity for the gamer.

The first step taken in order to meet our goals was to determine a game that could be used. Basically any good game (cf. Gee, 2003) would do, but we decided to choose Quest Atlantis (QA). QA is a very complex educational game. Very often, educational games are based on memorization and trivia, but QA offers a whole world where people can learn part of the things they are supposed to learn at school, but with the benefits of being immersed in the "real" world.

I have been using Quest Atlantis since the beginning of the year and I am still taking the teacher tutorial before I can actually start using the game with my students. Because of that, I chose an interaction from the teacher tutorial, where I will analyze the language used. At this point I feel I need to clarify that this paper does not try to be thorough at this point, it is more exploratory than final. The extract I chose was called Teacher PD Workshop Mission 2: Supporting Transformational Play.

Regarding the generic structure of the prompts, the procedure employed was to observe what was option al and what was not, and also what occurred more than once. As this work is still exploratory, the generic structure will probably not be final, as there may be more elements in other interactions which are not used in this one, or elements that emerge in this interaction, but not in others. What is important to keep in mind is that the generic structure proposed here attempts to characterize this particular exchange, and not all exchanges.

In what concerns the more detailed linguistic part, the data generated revealed itself to be analyzable in terms of the deictics, or shifters (Hanks, 1992; Ochs, 1992; Marmaridou, 2000) utilized.

\section{DATA ANALYSIS}

This section will look at two aspects of game prompts. Firstly, we will look at generic structure. We will do that by observing which elements are optional and which are mandatory, and will organize it according to Hasan's (1985) notation. After that, we will look into three kinds of deictics, social and person deictics, time deictics, and spatial deictics. These two steps will allow us to have an understanding of how these prompts are organized in terms of structure and also in terms of language, more specifically, in order to effectively position players as learners.

\section{Generic structure}


As shown above, SFL is concerned with how genres are organized into mandatory and optional elements. With that in mind, Hasan (1985) developed a notation for describing genres which shows how a genre can be structured, or, in other words, its generic structure. In order to show how we can do that, I will transcribe a few prompts below. The turns between quotation marks belong to the NPC Bronwyn, and the underlined ones are to be said (clicked) by the player. This patter of organization was taken straight from the game, they have just been copied.

Table 3: Generic structure

\begin{tabular}{|c|c|}
\hline Utterance & Function \\
\hline "Well, hello there" & Greeting \\
\hline $\begin{array}{l}\text { "You've certainly been busy since you arrived at the Transformational Play Institute! Picked up a } \\
\text { lot of useful information, too, no doubt." }\end{array}$ & Small talk \\
\hline "But now it's time for some fun!" & $\begin{array}{l}\text { Invitation for an } \\
\text { activity }\end{array}$ \\
\hline - $\quad$ Fun, huh? What do you have in mind? & $\begin{array}{l}\text { Request for } \\
\text { clarification }\end{array}$ \\
\hline $\begin{array}{l}\text { "Well, one of the questions we get asked most often by new teachers interested in Quest Atlantis } \\
\text { is, 'Can I observe a classroom to see how other teachers support the program?' } \\
\text { "Naturally, they want to see what a QA class looks like, so they can start imagining how it will look } \\
\text { in their own classes! Well, that's what I have to offer... classroom observations." }\end{array}$ & Clarification \\
\hline - $\quad$ That's great! Just what I want to see. & $\begin{array}{l}\text { Acceptance of } \\
\text { the invitation }\end{array}$ \\
\hline $\begin{array}{l}\text { "Ah... but I'm not offering to show you just any old class... } \\
\text { "What I've got here is a collection of five teachers demonstrating some of the most powerful } \\
\text { QA teaching strategies a teacher can utilize!" }\end{array}$ & Clarification \\
\hline - $\quad$ Really? Tell me more, Bronwyn! & $\begin{array}{l}\text { Request for } \\
\text { clarification }\end{array}$ \\
\hline $\begin{array}{l}\text { "Hey... we're all friends and colleagues at the TPI. Call me Bron! } \\
\text { "As I was saying, you'll find five great strategies here on my TV screens. Each of them is a } \\
\text { powerful tool for supporting student learning with our curriculum. I'd like you to take a look at all of } \\
\text { them. }\end{array}$ & Clarification \\
\hline $\begin{array}{l}\text { "Tell us what you think... which teaching strategy shown on my videos do you consider to be the } \\
\text { most important tool a teacher can use to ensure learning occurs in a Quest Atlantis adventure?" }\end{array}$ & $\begin{array}{l}\text { Feedback } \\
\text { request }\end{array}$ \\
\hline "In fact, why don't you evaluate them while you're at it?" & $\begin{array}{l}\text { Invitation for an } \\
\text { activity }\end{array}$ \\
\hline - $\quad$ That's easy! I'd say.... & $\begin{array}{l}\text { Accpetance of } \\
\text { the invitation }\end{array}$ \\
\hline $\begin{array}{l}\text { Which one of the teaching strategies you reviewed would you be MOST likely to use in your } \\
\text { classroom? } \\
\text { Class Debrief } \\
\text { Monitoring Progress } \\
\text { Groupwork } \\
\text { Socratic Questioning } \\
\text { Teachable Moments }\end{array}$ & $\begin{array}{c}\text { Feedback of the } \\
\text { activity }\end{array}$ \\
\hline
\end{tabular}




\begin{tabular}{|c|c|}
\hline $\begin{array}{l}\text { [She smiles.] } \\
\text { "Oh, thank you, UFRJDaniel. This information will be very helpful! }\end{array}$ & $\begin{array}{c}\text { Appraisal of the } \\
\text { contribution }\end{array}$ \\
\hline $\begin{array}{l}\text { "And you know... you might find it interesting to visit the teacher bulletin boards yourself from time- } \\
\text { to-time, to see what your QA colleagues have to say on teaching strategies, learning styles, } \\
\text { pedagogy, and a whole range of things!" } \\
\text { "The bulletin boards are easy to find. There's a link right on your Q-Pod. Check them out } \\
\text { whenever you're interested in sharing your thoughts with your peers." }\end{array}$ & $\begin{array}{l}\text { Invitation for an } \\
\text { activity (further } \\
\text { learning) }\end{array}$ \\
\hline That sound interesting. I will! & $\begin{array}{l}\text { Acceptance of } \\
\text { the invitation }\end{array}$ \\
\hline $\begin{array}{l}\text { "All right, then. I think I've taken up enough of your time chatting about teaching strategies!" } \\
\text { "Your QA training is almost complete. Just one more person to talk to here at the TPI. My friend } \\
\text { Lindsey has some valuable information to share about ensuring your students' safety while they're } \\
\text { online." } \\
\text { "Just head back down the hall to the big I-BURST poster you can see at the far end. Lindsey is } \\
\text { standing ready to give you your final bit of QA teacher training!" } \\
\text { Okay, thanks, Bron. I'll go talk to Lindsey. }\end{array}$ & Closure \\
\hline
\end{tabular}

As can be seen in the table above, the first step to determining which elements occur in the interaction, and which areoptional or recurrent, we used a framework which is very close to the one fostered by the ESP tradition. However, our focus is not on where these rhetorical moves should be located in the genre, but rather what functions they fulfill. Therefore, based on the table above, it is possible to see that most rhetorical moves appear only once, except for "invitation for an activity", "acceptance of the invitation", "request for clarification" and "clarification".

So, the generic structure, according to this interaction, will look like this:

Greeting $\wedge$ Small talk $\wedge$ \{[Invitation for an activity $\wedge$ (Request for clarification) $\wedge^{\wedge}$ (Clarification) $\wedge^{\wedge}$ (Acceptance of the invitation) $\left.]^{\mathrm{n}}\right\}^{\wedge}$ Feedback request $\wedge^{\wedge}$ Feedback of the activity $\wedge^{\wedge}$ Appraisal of the contribution ${ }^{\wedge}$ Closure

The structure offered above reads in the following manner: the only optional elements of the structure are "request for clarification", "clarification", and "acceptance of the invitation". While the possibility for refusal of the invitation does not appear in the discourse, if the player does not want to accept the activity, all they have to do is walk away. Naturally, they would be stuck in the game by doing that. The sequence within brackets, [Invitation for an activity $\wedge$ Request for clarification ${ }^{\wedge}$ Clarification ${ }^{\wedge}$ (Acceptance of the invitation)] can be repeated as many times as need be. This same extract can occur in other parts of the interaction. In our interaction above, it also appears right after the appraisal of the player's contribution. Finally, we can see that the interaction will start with a greeting, followed by some small talk. After that, in comes the extract described above, which can happen $n$ times and which can occur in other parts of the interaction, followed by an optional feedback request and the optional appraisal of this feedback.

Now that we have determined the generic structure of this particular interaction, we will move on to a more detailed analysis of the language. This, as has been said before, will consist in an analysis of the deictics.

\section{Social and Person Deictics}

The first part of the analysis, as stated above, was to look at deictics. The first class of deictics studied were person and social deictics (Marmaridou, 2000). According to Marmaridou, originally, there was a separation betweem social and person deixis, but this distinction was motivated by objetivist approaches to language. Here we will follow Marmaridou in her position and analyze both at the same time.

First of all, the NPCs (non-playing characters) all have names.In this specific interaction, I talked to Bronwyn, who is in charge of the videos in the teachers' institute in QA.

Table 4: First turn between player and Bronwyn.

\section{Bronwyn}

"Well, hello there! You've certainly been busy since you arrived at the Transformational Play Institute! Picked up a lot 
of useful information, too, no doubt.

"But now it's time for some fun!"

As can be seen above, the player is positioned as equal to Bronwyn, who is an expert teacher in the world of QA. This happens by the use of social deictics which index a friendly interaction between peers, such as "hello there", the use of the contraction in "You've" and the conversational omission of the subject in "Picked up a lot of useful information, too, no doubt". These deictics are shown in italics above.

The distance between player and expert is dimished even further when, in the fourth turn, Bronwyn asks the player to call her "Bron". This is not the only change enacted in this turn; Bronwyn stops using the deictics "I" and "you", which would put Bronwyn and the player in different groups, and uses the personal pronoun "we".

Table 5: Bronwyn changes her footing even more.

\section{Bron}

"Hey... we're all friends and colleagues at the TPI. Call me Bron!

"As I was saying, you'll find five great strategies here on my TV screens. Each of them is a powerful tool for supporting student learning with our curriculum. I'd like you to take a look at all of them.

"In fact, why don't you evaluate them while you're at it?"

As can be seen above, the player is positioned to act as an expert teacher as Bron decides to include the player in the the group. The other strategies continue to be used, that is, the use of expressions that are conversational and the use of contractions. The footing of expert teacher is fostered even more when Bron invites the player to take action in process by watching a slection of videos and evaluating them. Evaluating is something that teachers have to do often, and recognizing that the player can do it is to recognize that the player can take on that identity.

\section{Time deictics}

Time deictics also play an important role in situating the player in the learning process, as can be seen in the italicized words below. All turns are produced by Bron, expect for the underlined one, which is produced by the player.

Table 6: Use of deictics to position the player in the game world

\section{but I'm not offering \\ Tell us \\ be sure to come back \\ take a few minutes}

"But now it's time for some fun!"

That's great! Just what I want to see.

Above you can see a few deictics that help situate the player as an active learner. As Brown et al (1989) argue, video games are unique learning environments because the learning that place is used to solve a problem right away, and not somewhere in the future. Therefore, the use of deictics like the adverb "now", present tense verbs "I want to see" and "I'm not offering", as well as imperatives, "tell". "be", "take" situate the learning experience in the here and now.

\section{Spatial deictics}

Spatial deictics might be the most controversial point to discuss. To begin with, the fact that there is an avatar controlled by the player is already opinting everywhere and situating the player in the interaction. So, in short, spatial deixis is ubiquitous in video games. However, spatial deixis is also enacted discursively, as can be seen below. 
Table 7: Spatial deictics.

Well, that's what I have to offer... classroom observations

come back

Just one more person to talk to here at the TPI

The table above shows a few cues that can be considered spatial deictics. The first one is "classroom observations". These observations are done, in fact, within the game, so it also helps situate the learning process. The other two are less controversial, as their "basic meaning" is already spatial. These last two deictics are "come back" and "here". All in all, by using these deictics, Bron is helping situate the player within that world.

\section{CONCLUSION}

This paper set to observe how Quest Atlantis (QA) developers structure their prompts in order to immerse the player in a learning experience. The first part of our analysis revealed that invitations for activities are common. This finding resonates with the belief of researchers who believe in the importance of situated learning (Gee, 2003; Brown, 1989; Barab et al, 2013; 2010; Siyahhan et al, 2011; 2010). In other words, the player is seen an empowered actor who does lots of activities. Another important aspect noted in the data was that an appraisal of the player's contribution is offered, something is often absemt from classrooms, where teachers tend to pointing out mistakes instead of pointing out what has already been achieved.

Concerning the analysis of language at the sentence level,it waspossible to observe that deictics play a major role in the experience, helping anchor the player in the digital world of QA. This was done by stating that both player and expert teacher belonged to the same group, besides stating that the player shared essential characteristics expected of a teacher, such as the ability to evaluate teaching strategies ("In fact, why don't you evaluate them while you're at it?"), the fact that the player would be interested in checking out what other teachers think ("And you know... you might find it interesting to visit the teacher bulletin boards yourself from time-to-time, to see what your QA colleagues have to say on teaching strategies, learning styles, pedagogy, and a whole range of things!"). Finally, it is important to note that the language used is largely conversational, which supports the idea that there is not an ideal language for communication, but rather many possible variations. QA is a successful learning experience which does not need to lean on purist notions of language, and that is probably one of the most important characteristics of the QA experience.

Our account of the language used in QA, however, is still at its beginning, and more prompts need to be analyzed before a final conclusion is reached. Still, the understandings raised in this paper should be able to help game developers and instruction designers think about - if not change - the way they think language should be used in games and learning materials.

\section{ACKNOWLEDGMENTS}

I would like to thank the Quest Atlantis team for bringing such a good educational video game to life.

\section{REFERENCES}

[1] Alexander, J.; McCoy, M. \& Velez, C. 2007 "A real effect on the gameplay: Computer gaming, sexuality, and literacy" In Selfe, C. L. \& Hawisher, G. E. (Eds.) 2007 Gaming Lives in the Twenty-First Century. New York: Palgrave Macmillan, 167-190.

[2] Blackmon, S. \& Terrell, D. J. "Racing toward representation: Na understanding of racial representation in vídeo games” In: Selfe, C. L. \& Hawisher, G. E. (Eds.) 2007 Gaming Lives in the Twenty-First Century. New York: Palgrave Macmillan, 203-216.

[3] Bakhtin, M. 1979[1992] Estética da Criação Verbal. São Paulo: Martins Fontes.

[4] Barab, S. A., Pettyjohn, P., Gresalfi, M., Volk, C. \& Solomou, M. 2012 "Game-based curriculum and transformational play: Designing to meaningfully positioning person, content, and context" Computers \& Education, 5, 518-533.

[5] Barab, S. A., Gresalfi, M., Ingram-Goble, A. 2010 "Transformational play and: Using games to position person, content, and context. Educational Researcher, 39(7), 525-536.

[6] Bauman, R. 1986 Story, Performance and Event: Contextual Studies of Oral Narrative. Cambridge: CUP.

[7] Brown, J. S., Collins, A., \& Duguid, P. (1989). "Situated cognition and the culture of learning". Educational Researcher, 18(1), 32-42. 
[8] Gee, J. P. 2003 What Video Games Have to Teach us about Learning and Literacy. New York: Palgrave Macmillan.

[9] Goffman, E. 1981 Forms of Talk. Philadelphia: University of Pennsylvania Press.

[10] Gumperz, J. 1992 “Contextualization and understanding” In: Duranti, A. \& Goodwin, C. (Eds.) Rethinking Context: Language as an Interactive Phenomenon. Cambridge University Press. 229-252.

[11] Hanks, W. F. 1992 "The indexical ground of deictic reference". In: Duranti, A. \& Goodwin, C. (Eds.) Rethinking Context: Language as an Interactive Phenomenon. Cambridge University Press, $43-77$.

[12] Hasan, R. 1985 Linguistics, Language and Verbal Art. Geelong: Deakin University Press.

[13] Hoey, M. 2004 Textual Interaction: An Introduction to Discourse Analysis. London: Routledge.

[14] Hyon, S. 2000 "Genre in three traditions: Implications for ESI". TESO Quarterly 30, 4: 693-722.

[15] Langellier, K. M. "You're marked'. Breast cancer, tattoo, and the narrative performance of identity. In: Brockmeier, J. \& Carbaugh, D. (Eds.) 2001 Narrative and Identity: Studies in Autobiography, Self and Culture. Amsterdam: John Benjamins, 145-184.

[16] Makoni, S. \& Pennycook, A. "Disinventing and reconstituting languages". In Makoni, S. \& Pennycook, A. (Eds.) 2006 Disinventing and Reconstituting Languages. Great Britain: MPG Books.

[17] Marmaridou, S. S. A. 2000 Pragmatic Meaning and Cognition. John Benjamins.

[18] Ochs, E. "Indexing gender". In Duranti, A. \& Goodwin, C. (Eds.) Rethinking context: Language as an interactive phenomenon. Cambridge University Press, 335-358.

[19] Pratt, M. L. "Linguistic utopias". In: Fabb, N. et al 1987 The Linguistics of writing. Manchester: MUP.

[20] Rojo, R. "Fazer linguística aplicada em perspectiva sócio-histórica: privação sofrida e leveza de pensamento". In Moita Lopes, L. P. Por uma Linguística Aplicada Indisciplinar. São Paulo: Parábola, 2006 [2008].

[21] _. 'Gêneros do discurso/texto como objeto de ensino de línguas: um retorno ao trivium?' In: Signorini, I. [Re]Discutir Texto, Gênero e Discurso. São Paulo, Parábola, 2008.

[22] Signorini, I. 'A questão da língua legítima na sociedade democrática: um desafio para a linguística aplicada contemporânea'. In: MOITA LOPES, L. P. Por uma Linguística Aplicada Indisciplinar. São Paulo: Parábola, 2006 [2008].

[23] Siyahhan, S., Barab, S. A. \& James, C. Youth and the ethics of identity play in virtual spaces. Journal of Interactive Learning Research, 22(1), 111-138.

[24] Siyahhan, S., Barab, S. A. \& Downton, M. P. 2010 Using activity theory to understand intergenerational play: The case of Family Quest. Computer-Supported Collaborative Learning, 5, 415-432.

[25] Thornborrow, J. \& Coates, J. The sociolinguistics of narrative, identity, performance, culture. ". In Thornborrow, J. \& Coates, J. (Eds.) 2005. The Sociolinguistics of Narrative. Amsterdam: John Benjamins, 1-16.

[26] Threadgold, T. "Performing theories of narrative: Theorizing narrative performance". In Thornborrow, J. \& Coates, J. (Eds.) 2005. The Sociolinguistics of Narrative. Amsterdam: John Benjamins, 261-278.

[27] Wittgenstein, L. Philophical Investigations. Oxford, Basil Blackwell: 1953.

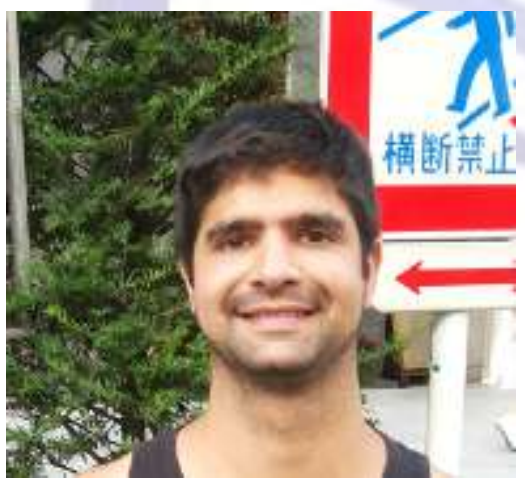

Author' biography with Photo

Daniel de Augustinis Silva holds a Master's degree in Linguistics from the State University of Rio de Janeiro. He is now an Assistant Professor at the Federal University of Rio de Janeiro, where he teachers ESP to students of various courses, such as Chemistry, Pharmacy, Nutrition and Biology, among others. 